
\title{
25 Research Sourere \\ The efficiency and mechanism of vermicompost in enhancing the composting of swine manure as an additive
}

\section{Xiaoxia Hao}

Sichuan Agricultural University

\section{Xinyuan Ma}

Sichuan Agricultural University

\section{Lin Bai (D14124@sicau.edu.cn )}

Sichuan Agricultural University

\section{Research Article}

Keywords: Vermicompost, Composting, Manure, Bacterial community, Metabolic functional genes, Network analysis

Posted Date: February 18th, 2021

DOI: https://doi.org/10.21203/rs.3.rs-160415/v1

License: (9) This work is licensed under a Creative Commons Attribution 4.0 International License. Read Full License

Version of Record: A version of this preprint was published at Environmental Science and Pollution Research on July 28th, 2021. See the published version at https://doi.org/10.1007/s11356-021-14498-x. 


\section{Abstract}

Vermicompost was used as an additive in swine manure composting, and the expression of bacterial functional genes on biotransformation of nutrient was investigated. Results showed that vermicompost extended the thermophilic period to 12 days, decreased the $\mathrm{NH}_{4}{ }^{+}-\mathrm{N} / \mathrm{NO}_{3}{ }^{-}-\mathrm{N}$ ratio to 0.85 and increased GI value to $166 \%$. With vermicompost addition, higher relative abundances of Firmicutes were observed in substrate at the beginning. The dominant phyla of Proteobacteria was decreased in thermophilic stage, as well as its pathogenic related genera Acinetobacter and Stenotrophomonas, while the potentially beneficial genera Actinomadura and Chryseolinea were increased. And the activities of primary functional genes associated with metabolisms of carbohydrate, amino acid and xenobiotics at the level 2 and fatty acid metabolism at the level 3 were enhanced during the thermophilic phase. Besides, most dominant genera showed strengthened correlations with $\mathrm{NO}_{3}{ }^{-}-\mathrm{N}$ and $\mathrm{Gl}$ with vermicompost amendment, and they were the strongest environmental factors for bacterial communities. Network analysis showed dominant genera Pseudomonas, Acinetobacter, Stenotrophomonas Oceanobacter associated metabolic pathways increased from two to three with vermicompost added in substrate. These results indicated that vermicompost promoted the composting efficiency by increasing the potentially beneficial bacteria, decreasing pathogenic bacteria and enhancing the metabolic capacity of bacterial communities.

\section{Introduction}

Composting is one of the cost effective ecofriendly strategies for the disposal of organic waste, which fits with 3R's philosophy (Reduce, Reuse and Recycle), and produces stabilized end product (Awasthi et al., 2014). To enhance the composting process, biochar is a popular additive for promoting the degradation of organic wastes based on its high surface areas and porosity properties (Zhou et al., 2019). Moreover, mature compost is another option for compost amendment as reported by Liu et al. (2018b), who revealed that the compost could introduce favorable microorganisms. In practical organic fertilizer production, the composts are usually used as additives to induce the whole composting.

Comparing with biochar and composts, vermicompost not only has the characteristics of high surface areas and porosity, but also attaches abundant beneficial microorganisms (Pathma and Sakthivel, 2012). The porosity and high surface areas can provide a habitat for the beneficial microorganisms, allowing more oxygen into the substrates and further stimulating microbial activity (Edwards and Burrows, 1988). Besides, different from the biochar obtained by firing at high temperature, the vermicompost is low cost and much eco-friendly. As a physically, nutrition and biochemically allied stabilized product, the vermicompost is the final product obtained by subjecting organic wastes to mesolytic composting through the digestive system of earthworms (Aira and Domínguez, 2009). It is reported the vermicompost contains nutrition content, enzymes and hormones, and are capable of improving soil health and nutrient status (Gajalashkmi and Abbasi, 2004). Studies were focused on the application of vermicompost as organic fertilizer or soil improver. Vermicompost was proved can improve the soil structure, prevent soil from erosion, and promote plant growth and their resistance to pathogens (Singh and Singh, 2017). 
However, little information can be found about the effect of vermicompost amendment on composting process when it was used as an additive.

Previous studies revealed that the bacterial community compositions and structures of swine manure can be varied by sawdust, wheat straw, bamboo biochar, spent mushroom substrate and rice husks in the composting process (Chen et al., 2018; Guo et al., 2017; Mao et al., 2018; Meng et al., 2018). The degradation of organic substrates is dominated by bacterial community in the composting process, and metabolic functions of microorganisms derived by the transcription and expression of corresponding functional genes (Zhu et al., 2019). Therefore, the research on various functional genes during composting process is of great significance to analyze and further deep understand the mechanism of this biotechnology. Research on effect of vermicompost on metabolic functional genes is limited.

A composting was conducted in 30 days to study the degradation of swine manure and its mechanism with vermicompost amendment. The aims of this study were to investigate: (1) the promotion on formation of mature compost by improving the composting internal conditions; (2) the increase of beneficial bacterial communities and decrease of harmful bacterial communities; (3) dynamic of metabolic functional genes at the major three stages of swine manure composting.

\section{Materials And Methods}

\section{Composting materials and experimental set-up}

The swine manure (SM) and swine manure vermicompost were obtained from the farm of Sichuan Agricultural University (SAU, Ya'an, Sichuan, China). Wood chips were purchased from local wood processing factory in Ya'an city and used to adjust the $\mathrm{C} / \mathrm{N}$ ratio. The substrates $(500 \mathrm{~kg})$ with a $\mathrm{C} / \mathrm{N}$ ratio of roughly 25-30 were obtained by mixing some wood chips into the swine manure. Vermicompost (80 $\mathrm{kg}$ ) was prepared by vermicomposting using some of the substrates and earthworms (E. fetida) for 30 days. The main characteristics of the raw materials were presented in Table 1.

Table 1

Properties of raw materials for composting

\begin{tabular}{|lllllll|}
\hline Raw materials & Moisture (\%) & pH & TOC(\%) & TN(\%) & C/N & TP(\%) \\
\hline Swine manure & $74.42 \pm 0.70$ & $8.08 \pm 0.03$ & $53.61 \pm 1.32$ & $2.17 \pm 0.02$ & 24.71 & $1.99 \pm 0.01$ \\
\hline Wood chips & $10.09 \pm 0.57$ & $5.88 \pm 0.07$ & $73.25 \pm 1.35$ & $0.13 \pm 0.01$ & 563.46 & - \\
\hline Vermicompost & $58.31 \pm 1.58$ & $8.55 \pm 0.09$ & $42.40 \pm 1.82$ & $3.72 \pm 0.03$ & 11.40 & $2.75 \pm 0.01$ \\
\hline
\end{tabular}

Four treatments (CK, T1, T2 and T3, 30-40 kg of each) with the vermicompost ratio of $0,10 \%, 20 \%$ and $30 \%$ were set up, respectively. The initial properties were slightly changed by vermicompost. Each treatment was conducted in triplicates. The foam boxes measuring $60 \mathrm{~cm} \times 40 \mathrm{~cm} \times 40 \mathrm{~cm}$ (inside size) 
were used as composting containers, and five holes were distributed at the bottom of each box for ventilation.

\section{Samples collection and physico-chemical parameter analysis}

Composts in container were manually turned over after each sampling to guarantee enough oxygen. The samples were collected on days $1,5,10,15,20,25$ and 30 during the composting process. Nine samples from top, middle, and bottom of each container were collected (about $200 \mathrm{~g}$, wet weight), some of them were used for determination of moisture content, and others were air dried, crushed and then passed through soil sieves $(0.425 \mathrm{~mm})$ to detect the physicochemical properties. Fresh samples collected in the same way from days 0,10 and 30 were immediately processed for microbiology testing.

The temperatures of composting piles and surrounding environment were recorded at 9:00 am and 5:00 pm every day, respectively. The $\mathrm{pH}, \mathrm{EC}$, moisture content, total organic carbon (TOC), total nitrogen (TN), $\mathrm{NH}_{4}{ }^{+}-\mathrm{N}$ content, $\mathrm{NO}_{3}{ }^{-}-\mathrm{N}$ content, total phosphorus (TP) and seed germination index (GI) were measured using previous research methods (Bremner and Mulvaney, 1982; Liu et. al., 2018a).

\section{DNA extraction and high-throughput sequencing}

Total DNA was extracted from $2 \mathrm{~g}$ fresh samples using the PowerSoil® DNA Isolation kit (Califonia, USA) according to the manufacturer's instructions. Bacterial 16S rRNA genes were amplified using primer $515 \mathrm{~F}$ (5'-GTG CCA GCM GCC GCG GTA A-3') and 806R (5'-GGA CTA CHV GGG TWT CTA AT-3') at a final reaction volume of $50 \mathrm{ml}$. The PCR program was 30 cycles of $95^{\circ} \mathrm{C}$ for $7 \mathrm{~min}, 94^{\circ} \mathrm{C}$ for $1 \mathrm{~min}, 55^{\circ} \mathrm{C}$ for $1 \mathrm{~min}$, and $68^{\circ} \mathrm{C}$ for $8 \mathrm{~min}$. The PCR products were identified by $1 \% \mathrm{wt} / \mathrm{vol}$ Agarose-Gel Electrophoresis. The obtained amplicons from each single collection were submitted for sequencing using a HiSeq platform (PE250, Illumina, USA).

\section{Processing of sequence data}

The raw Illumina FASTQ files of high-quality sequences were analyzed using quantitative insights into microbial ecology (QIIME) (version 1.9.0) after demultiplexing and quality filtering. A $97 \%$ threshold was applied to cluster the quality filtered sequences into operational taxonomic units (OTUs) (Langille et al., 2013), and then screen for chimeras using the Usearch9.0 software and RDP database. The diversity differences were analyzed by using Mann-Whitney Utest based on Shannon, Chao 1 and coverage estimator (ACE) methods. To assess beta diversity, we computed weighted unifrac, and visualized the matrices using Principal Co-ordinates analysis (PCoA). And two-sided Welch's $t$-test was used to identify species that were significantly represented among different groups. The function characteristics of bacterial community during composting were analyzed by PICRUSt. Specifically, the first and second class metabolic pathways of bacterial community were generated by using the Kyoto Encyclopedia of Genes and Genomes (KEGG) after normalizing OTU table, and STAMP software was used to get the metabolic pathways of class three. Redundancy analysis (RDA) and Mantel test was used to assess the correlations between environmental factors and bacterial community composition. The correlation between the main genera and environmental parameters were measured by Spearman method. Network analysis was performed using MINE software, and the network was Visualized using Cytoscape (v.3.2.1). 


\section{Statistical analysis}

All measurement data were shown as mean \pm standard deviation. Significant differences in the physicochemical properties of composts were assessed by analysis of variance using SPSS v. 22.0 (Armonk, NY: IBM Corp.) at the $5 \%$ probability level $(P<0.05)$.

\section{Results}

\section{Changes of physicochemical characteristics and seed germination index (GI) during composting}

The physical properties of treatments during composting were recorded in Fig. 1 and Fig. S1. Comparing with the ambient temperature, the pile temperatures increased rapidly at the beginning two days, and thermophilic temperatures over $50^{\circ} \mathrm{C}$ was maintained for $11-12$ days in $\mathrm{T} 1, \mathrm{~T} 2$ and $\mathrm{T} 3$, and 8 days in $\mathrm{CK}$ (Fig. 1a). The maximum temperatures for $\mathrm{T} 1$ and $\mathrm{T} 2$ were $63.1^{\circ} \mathrm{C}$ and $61.6^{\circ} \mathrm{C}$ on day 7 , which were much higher than that in $\mathrm{CK}\left(58.8^{\circ} \mathrm{C}\right)$. In composting process, the moisture content decreased with time, and more reductions were obtained as follows: $\mathrm{T} 3>\mathrm{T} 2>\mathrm{T} 1>\mathrm{CK}$ at the end of the experiments (Fig. 1b). The EC increased about $1.0 \mathrm{mS} \mathrm{cm}^{-1}$ in the initial 15 days (Fig. S1b). Comparing with the CK treatment, lower final $E C$ values were detected in $\mathrm{T} 1, \mathrm{~T} 2$ and $\mathrm{T} 3$ ranging from $1.81 \mathrm{mS} \mathrm{cm}^{-1}$ to $2.17 \mathrm{mS} \mathrm{cm}^{-1}$.

The concentrations of nutrients in piles were analyzed during composting. More $(p<0.5)$ TOC decreases in 30 days were observed in T1 $(25.64 \%)$ and T2 $(21.42 \%)$, respectively, comparing with in CK $(16.00 \%)$ (Fig. S1c). The TN decreased and then increased until the end in all groups (Fig. S1d). With vermicompost as an additive in swine manure, $\mathrm{C} / \mathrm{N}$ ratio dropped to $17.70-18.95$ on the day 20 in $\mathrm{T} 1, \mathrm{~T} 2$ and $\mathrm{T} 3$, while it dropped to 19.74 on the day 25 in $\mathrm{CK}$ (Fig. 1c). Moreover, the final $\mathrm{NO}_{3}{ }^{-} \mathrm{N}$ concentrations were increased $(p<0.05)$ more in T2 $(299 \mathrm{mg} / \mathrm{kg})$ and T1 $(282 \mathrm{mg} / \mathrm{kg})$ than in CK $(220 \mathrm{mg} / \mathrm{kg})$, while no obvious differences in $\mathrm{NH}_{4}{ }^{+}-\mathrm{N}$ concentrations (ranged from 213-2281 mg/kg) were observed among treatments (Fig. S1e, f). Correspondingly, the $\mathrm{NH}_{4}{ }^{+}-\mathrm{N} / \mathrm{NO}_{3}{ }^{-}-\mathrm{N}$ ratio or nitrification index (NI) of $\mathrm{T} 1, \mathrm{~T} 2, \mathrm{~T} 3$ were 0.94 , $0.85,0.87$, respectively, greatly lower $(p<0.05)$ than that in CK $(2.10)$ (Fig. 1d). Besides, higher TP concentration in T1 (2.87\%) and T2 (3.01\%) were detected on day 30 (Fig. 1e).

In this study, the $\mathrm{GI}$ values in all treatments generally increased during the composting period (Fig. 1f). And more $(p<0.05)$ GI value increases were obtained in T2 $(166 \%)$ and T1 $(152 \%)$ at the end of composting. Taking a GI value higher than $120 \%$ to signal mature compost, more rapid attainment of mature compost was obtained in T2 (122\%) on day 15 , and in T1 (135\%) on day 20 , whereas immature compost was observed in CK (90\%) and T3 (116\%) on day 30.

\section{Dynamics of bacterial community with vermicompost amendment}

In this study, totally 108 samples (9 samples from each group on day 0, 10 and 30 , respectively) were collected for $16 \mathrm{SrRNA}$ high-throughput sequencing. A total of $8,428,705$ reads were produced. After chimera checking and filtering out singleton OTUs, a total of 8,428,700 clean reads were retained in the dataset. Each sample had 78,044 reads on average. The a-diversity results (Fig. S2) showed that the richness (OTUs, Ace and Chao1) and diversity (Shannon) of bacteria in T group decreased continuously 
during the composting, while they increased and then decreased in CK. Both the OTU numbers and the indexes of Shannon, Chao1 and Ace of T0 was greatly $(p<0.01)$ higher than that in CK0. However, Chao1 index and OTUs of T10 were lower $(p<0.05)$ than CK10 (Fig. S2b \& d), and Shannon index and OTUs of T30 were lower $(p<0.05)$ than CK30 (Fig. S2a \& d). The PCoA demonstrated that samples in T clustered differently from in CK on day 0,10 and 30 (Fig. S2e).

A total of 48 bacterial phyla were observed in all samples. Four dominant phyla accounted for $85.2 \%$ $96.5 \%$ of the total sequences, including Proteobacteria, Bacteroidetes, Firmicutes and Actinobacteria were revealed in all groups (Fig. 2a). At the genus level, 610 genera were observed, and the top10 including Pseudomonas, Acinetobacter, Clostridium_sensu_stricto_1, Actinomadura, Chryseolinea, Luteimonas, Flavobacterium, Stenotrophomonas, Oceanobacter and Paenibacillus were further investigated (Fig. 2b). Changes in relative abundances with vermicompost amendment were observed by linear discriminant analysis (LDA) effect size (LEfSe) (Fig. S3). The abundant phyla were Firmicutes in T0 and T30, Gemmatimonadetes in T10 and T30, Actinobacteria in T10 and CK10, Proteobacteria in CK10 and CK30, Bacteroidetes in CK10, CK30 and T30.

Specifically, $t$-test results showed the only varied phylum in initial samples was Firmicutes whose relative abundance in TO $(12.36 \%)$ was higher $(p<0.05)$ than in CKO $(8.85 \%)$. During the thermophilic phase, significant difference $(p<0.05)$ in the abundances of Proteobacteria, Actinobacteria and Gemmatimonadetes were observed between CK10 (51.02\%, 6.97\%, 2.46\%) and T10 (36.87\%, 13.15\%, $8.74 \%$ ). Moreover, no big differences were found in the initial materials (TO and CKO) at the genus level. In vermicompost amendment samples, lower $(p<0.05)$ relative abundances of Acinetobacter, Stenotrophomonas, Flavobacterium were detected in T10 (1.82\%, 0.72\%, 0.66\%) than in CK10 (4.17\%, $1.27 \%, 1.07 \%)$, while higher $(p<0.05)$ Actinomadura was observed in T10 (4.16\%) than in CK10 (0.85\%). And Luteimonas, Stenotrophomonas, Oceanobacterhad significant $(p<0.05)$ lower $(p<0.05)$ abundances in T30 (2.42\%, 0.27\%), compared to CK30 (4.29\%, 0.86\%), whereas higher $(p<0.05)$ abundances of Chryseolinea and Clostridium_sensu_stricto_1 in T30 (7.33\%, 3.20\%) were observed than in $\operatorname{CK} 30(0.93 \%, 2.27 \%)$.

\section{Dynamics of functional genes with vermicompost amendment}

The predicted biochemical metabolic pathways in samples were similar, including metabolism (73.2$75.6 \%, 12$ pathways), genetic information processing (9.5-10.6\%, 4 pathways), environmental information processing (7.4-8.7\%, 3 pathways), human diseases (3.1-3.3\%, 11 pathways), cellular processes (2.4-3.4\%\%, 4 pathways) and organismal systems (1.3-1.6\%, 8 pathways) (Fig. S4a, b). At the level 3, totally 337 metabolic functions were revealed, and the 20 most abundant functions were illustrated in Fig. 3.

The dynamic of metabolic functions at the level 2 and 3 were observed mainly during the thermophilic phase (Fig. 3). Obviously, the abundances of carbohydrate metabolism, lipid metabolism, biosynthesis of other secondary metabolites, amino acid metabolism, metabolism of terpenoids and polyketides and xenobiotics biodegradation and metabolism belonging to the cluster of metabolism were significantly ( $p$ 
$<0.05)$ increased in $\mathrm{T} 10(13.54 \%, 3.90 \%, 1.18 \%, 12.49 \%, 2.31 \%, 3.20 \%)$ than in CK10 $(13.91 \%, 4.23 \%$, $1.30 \%, 12.78 \%, 2.48 \%, 3.81 \%)$. Meanwhile, sequences related to metabolism of cofactors and vitamins, nucleotide metabolism, translation, folding, sorting and degradation, replication and repair and cell motility were reduced $(p<0.05)$ from $6.73 \%, 4.89 \%, 4.32 \%, 2.25 \%, 3.78 \%, 2.23 \%$ in CK10 to $6.48 \%, 4.67 \%$, $4.09 \%, 2.04 \%, 3.63 \%, 1.91 \%$ in T10, respectively (Fig. 3a).

At the third level KEGG ortholog function predictions (Fig. 3b), 16 of the top20 pathways were belong to metabolism, two of them belong to genetic information processing, and the other two belong to environmental information processing. Comparing with CK10, significantly lower $(p<0.05)$ numbers of functional genes were detected in T10 except for those involved in fatty acid metabolism. For instance, biosynthesis of amino acids possessed richer $(p<0.01)$ genes number in CK10 (2656757) than in T10 (2165304). However, the relative abundance of genes assigned into fatty acid metabolism was higher in T10 than in CK10. And no big difference $(p>0.05)$ was found between CK0-T0 and CK30-T30.

\section{Relationship among the environmental factors, functional genes and bacterial communities}

As shown in Fig. 4a, both the samples on day 0 were strongly affected by TOC and moisture, but a closer correlation was observed in T0 than in CKO. Comparing with control groups, higher positive correlations were observed between $\mathrm{T} 10$ samples and $\mathrm{EC}, \mathrm{NH}_{4}{ }^{+} \mathrm{N}$, temperature, as well as between $\mathrm{T} 30$ samples and $\mathrm{Gl}, \mathrm{NO}_{3}{ }^{-}-\mathrm{N}, \mathrm{TP}, \mathrm{pH}$.

As illustrated in Fig. 4b, the strongest environmental factors for bacterial communities were $\mathrm{NO}_{3}{ }^{-}{ }^{-} \mathrm{N}$ and $\mathrm{Gl}$, which were positively related $(r>0.6, p<0.001)$ to Actinomadura, Nonomuraea and Clostridium_sensu_stricto_ 1 , and negatively related $(r>0.6, p<0.001)$ to Pseudomonas, Acinetobacter, Stenotrophomonas, Flavobacterium and Oceanobacter. In the vermicompost treatment, the correlations between Luteimonas, Actinomadura, Nonomuraea and most of the environmental factors were reduced, while the correlations between other seven genera and most of the environmental factors were enhanced. For instance, the associations between Pseudomonas and all the parameters were not significant $(p>$ $0.05)$ except for $\mathrm{NO}_{3}{ }^{-}-\mathrm{N}(\mathrm{r}=-0.42)$ and $\mathrm{GI}(\mathrm{r}=-0.34)$ in $\mathrm{CK}$ group. However, the correlation coefficients between Pseudomonas and $\mathrm{NO}_{3}{ }^{-} \mathrm{-}$ and $\mathrm{Gl}$ were strengthened to -0.61 in $\mathrm{T}$ group. With vermicompost amendment, the correlations between Pseudomonas and temperature, moisture, TOC, $\mathrm{pH}, \mathrm{EC}, \mathrm{TP}$ were strengthened to significantly $(p<0.05)$ as well.

To further explore the interaction between functional genes and microorganisms, the top 10 genera were selected for network structure visualization (Fig. 5). The genera affected one to three metabolic pathways in both CK and T. Obviously, the genera were significantly enriched in the environmental information processing and human diseases in $\mathrm{CK}$, while they were enriched in the environmental information processing, metabolism and organismal systems in T. The correlations among Pseudomonas, Acinetobacter, Stenotrophomonas Oceanobacter and metabolism and organismal systems were strengthened in $\mathrm{T}$, and the negative interrelationships were observed. Moreover, cellular processes were 
positively correlated to Paenibacillus and negatively correlated to Chryseolinea with vermicompost amendment in T.

\section{Discussion}

\section{Vermicompost accelerated the maturity of compost}

Temperature is an important factor accelerating the fermentation process and indicating good fermentation conditions during composting (Liu et. al., 2018a). These results indicated that the vermicompost increased temperatures of treatments rapidly and extended the thermophilic period at a higher temperature, which might be due to high porosity of vermicompost and more favorable microbial metabolisms in it (Adhikary, 2012; Edwards and Burrows, 1988). The continuous higher temperature and ventilation contributed to decline of moisture content of the pile (Ermolaev, 2019), and decreased moisture reductions with the vermicompost increasing in the treatments were associated with water retention capacity of vermicompost. Lower final EC values in treatments than in control probably as a result of more volatilization of ammonia and precipitation of mineral salts (Zhang et al, 2016).

The accelerated swine manure degradation by vermicompost addition led to more decreases of the TOC and increases of the TN and TP as the Fig. 1 \& S1 showed. So the contributions made by "concentration effect" to the final values of TN and TP was magnified (Li et al., 2012; Wang et al., 2016). The curves variations of $\mathrm{NH}_{4}{ }^{+}-\mathrm{N}$ and $\mathrm{NO}_{3}{ }^{-}-\mathrm{N}$ due to the ammonification, nitrification and denitrification functions were magnified by vermicompost as well (Chan et al., 2016; Ren et al., 2016).

The physicochemical factors were usually used to indicate maturity of compost. Harshitha et al. (2016) have revealed a $\mathrm{C} / \mathrm{N}$ ratio of 10-21 as an indicator of compost maturity. Das et al. (2011) used the nitrification index $(\mathrm{NI})$ to measure the maturity of compost in three ranges: fully mature compost $(\mathrm{NI}<$ $0.5)$, mature compost $(0.5<\mathrm{NI}<3.0)$ and immature compost $(\mathrm{NI}>3.0)$. In the present study, the final $\mathrm{C} / \mathrm{N}$ ratios and $\mathrm{NI}$ values in vermicompost treatments all indicated the composts reached the maturity standard, compared to control. And immature compost was observed by $\mathrm{C} / \mathrm{N}$ ratios in $\mathrm{CK}(21.74)$ on the day 20 and by NI values in CK (4.37) on the day 25, which showed that the vermicompost could help to reach the composts maturity standard at least 5 days earlier.

As one of the most sensitive assessment of the toxicity and maturity of composting, a GI value higher than $80 \%$ was generally used to indicate a compost of phytotoxin-free (Gu et al., 2011; Zhang and Sun, 2014). However, Qian et al. (2014) suggested the GI>120\% signal mature compost. Results in this study showed higher $\mathrm{GI}$ values were observed in T1 and T2 than in CK $(P<0.05)$, indicating vermicompost improved the phytotoxin-free and maturity greatly. All the results above support the conclusion that vermicompost promoted the composting efficiency of swine manure.

\section{Vermicompost decreased pathogens and increased potentially beneficial taxa}

The increased bacteria diversity of T0 indicated that some bacteria carried by vermicompost might be introduced into the manure. And lower diversity was found in T10 than in CK10, which may owe to the 
higher temperature of T10. It was reported a high temperature period during composting can lead to a decrease in a-diversity (Wang et. al., 2017). Besides, Wei et al. (2018) revealed the restricted environmental conditions in composting generally lead to more specific and homogeneous bacterial community. In this way, the lower diversity in T10 and T30 can be attributed to better environmental conditions for composting provided by vermicompost.

Relative abundances of phyla and genera varied between treatment and control, indicating bacterial succession was modulated by vermicompost. The significant $(p<0.05)$ abundance of Firmicutes in T0 demonstrated that it was carried by vermicompost, and may be benefit to the whole composting process. The family Clostridiaceae (belongs to the phylum Firmicutes) has been proved to have the ability to degrade cellulose during the composting (Xi et al., 2015). More abundance of Clostridium_sensu_stricto_ 1 belonging to family Clostridiaceae was observed in vermicompost added treatments during the whole composting process, especially in T30 $(P<0.05)$. Moreover, significant higher $(p<0.05)$ abundances of phylum Actinobacteria and its genus Actinomadura were observed in T10 with vermicompost addition. It has been reported Actinobacteria is capable of better decomposition of organic substrate in composting because they can form the spore in high temperature or reduced water content environments (Jurado et al., 2014), and Actinomadura can degrade plant residues such as cellulose and lignocelluloses (Anderson et al., 2011). Genus Chryseolinea was abundant in T30, while its family Cytophagaceae are capable of cellulose utilization and macromolecules digestion (Park et al. 2014). These results suggest that vermicompost can promote the decomposition of pig manure by increasing the abundances of potential probiotic bacterial communities.

On the other hand, phylum Proteobacteria and its genera Acinetobacter, Luteimonas and Stenotrophomonas decreased in T10 or T30 comparing to control. It was reported that various infections can be caused by Acinetobacter, which can also survive various common disinfectants frequently used in commercial pig farming to avoid disease (Teixeira and Merquior, 2014). Both the Luteimonas and Stenotrophomonas belong to family Xanthomonadaceae, which was related to the plant pathogen (Anderson et al., 2011). These results suggested that vermicompost is capable of reducing some potential pathogenic bacteria in composting, which can be explained by extended the thermophilic period at a higher temperature in T. Soobhany et al. (2017) found effective pathogen inactivation can be achieved if temperatures of composting system maintain greater than $55^{\circ} \mathrm{C}$ for at least 3 days. The compost temperatures greater than $55^{\circ} \mathrm{C}$ were maintained 8 days in $\mathrm{T} 1$ and $\mathrm{T} 2$ treatments in this study (Fig. 1).

\section{Vermicompost modulated the metabolic functional genes}

In this study, metabolic functions classified according to the type of KEGG pathways showed metabolism possessed richest and largest relative abundance of genes among six pathways, which was in accordance with Chen et. al (2020) who investigated effect of red kaolin on the diversity of functional genes. Compared to $\mathrm{CK}$, significant $(p<0.05)$ abundance variations of functional genes influenced by vermicompost were observed mainly during the thermophilic phase. Similar high relative abundances of metabolisms related to amino acid, lipid, carbohydrate, xenobiotics, terpenoids and polyketides in the 
thermophilic phase were observed by Wang et al. (2018) during swine manure composting, which suggested these metabolism pathways were good for the composting process. The enhanced biodegradation of organic substrates may attribute to the beneficial microbes, enzymes and hormones contained in the vermicompost (Olle, 2018). Vermicompost can be a potential promoter of bacterial metabolism. On the contrary, the abundances of nucleotide metabolisms, translation, folding, sorting and degradation, replication and repair and cell motility were significantly $(p<0.05)$ reduced in the treatment group. Similar reduction on these metabolic pathways was reported by biochar which was used as an additive for composting (Zhou et al. 2019). It suggests that the effect of vermicompost on some bacterial metabolic functions was in accordance with that of biochar during swine manure composting. And biochar has been proved can enhance the activity of beneficial functional genes through improving the internal environment as a modifier (Zhou et al. 2019).

Moreover, the top20 functional genes numbers at the third level showed that significant lower genes numbers $(p<0.05)$ were obtained in T10 compared to CK10, which may be attributed to the lower numbers of sequences in T10 during the thermophilic period. Totally 76972 and 66969 sequences were detected in CK10 and T10, respectively (Fig. S5). This result was due to the extended thermophilic period and higher temperature caused by vermicompost addition. Moreover, the relative abundance of functional genes at the third level were analyzed as well, most of the genes were not differed between CK and T. However, the relative abundance of sequences assigned into fatty acid metabolism were increased significantly $(P<0.001)$ in T10 compared to in CK10, while fatty-acid-metabolizing bacteria are related to disease suppression in compost (McKellar and Nelson, 2002). It indicated the vermicompost is a good modifier for bacterial metabolic functions.

\section{Vermicompost enhanced the correlations among the environmental factors, metabolic pathways and bacterial communities}

The improved correlations between T0 samples and TOC, moisture, $\mathrm{T} 10$ and $\mathrm{EC}, \mathrm{NH}_{4}{ }^{+} \mathrm{N}$, temperature, $\mathrm{T} 30$ and $\mathrm{Gl}, \mathrm{NO}_{3}{ }^{-} \mathrm{N}, \mathrm{TP}, \mathrm{pH}$ suggested that the substrates degradation during the thermophilic phase and the composts maturity during the maturation phase was promoted due to better environmental conditions were provided by vermicompost, which was in accordance with the results above.

The positive correlations between $\mathrm{NO}_{3}{ }^{-}-\mathrm{N}, \mathrm{GI}$ and bacteria suggested that composting process promoted the growth of the genera Actinomadura, Nonomuraea and Clostridium_sensu_stricto_1 as shown in Fig. 2, and the three genera might be good for substrates turning to maturity by fermentation and nitrification, which was revealed by Anderson et al. (2011) and Xi et al. (2015). Besides, the negative correlations suggested composting inhibited the growth of Pseudomonas, Acinetobacter, Stenotrophomonas, Flavobacterium and Oceanobacter (Fig. 2) while these genera might be bad for formation and increase of $\mathrm{NO}_{3}{ }^{-}-\mathrm{N}$ and $\mathrm{Gl}$. The Acinetobacter and Stenotrophomonas are pathogen related species that may secrete toxic substrate and affect the increase of GI (Anderson et al., 2011; Teixeira and Merquior, 2014). Opposite to the present study, Pseudomonas showed positive associations with the Gl in study of Zhang et. al (2020). It was due to the novel characteristic of Pseudomonas, whose strain Pseudomonas putida 
(NP5 and ZN1) possessed simultaneous nitrification and denitrification (Yang et al., 2019; Zhang et al., 2019). Denitrification might be the dominated nitrogen metabolism of Pseudomonas in this experiment. Moreover, Yang et al. (2019) also reported the phosphorus removal property of Pseudomonas putida strain NP5, similar negative correlations were observed between Pseudomonas and TP in Fig. 4b. Variation of correlations between Pseudomonas and temperature, moisture, TOC, pH, EC, TP from CK to T indicated that the activities of Pseudomonas were improved by vermicompost. Similar improvement was observed in most of the bacteria (Fig. 4b). Taking the results together, the enhanced bacterial activities by vermicompost contributed to the higher composting efficiency of swine manure.

Several dominant bacteria were correlation with two or three biochemical metabolic pathways in this study (Fig. 5), which was in agreement with Wei et al. (2018) who reported genera affected multiple metabolic pathways in composting process. There were positive interrelationships between environmental information processing and Pseudomonas, Acinetobacter, Stenotrophomonas Oceanobacter, suggesting that environmental information processing played an important role in evolutions of these genera. Different from in CK group, the negative correlation between these four genera and metabolism was generated in $\mathrm{T}$, and the associated metabolic pathways increased from two to three. It can be concluded that the metabolic activities of bacterial communities were enhanced by vermicompost addition. The metabolism allowed these bacteria to grow, reproduce, maintain their physiological structures, and respond to the changing environment (Li et al., 2016). The above conclusion was supported by strengthened correlation between the dominant genera and environmental parameters.

\section{Conclusion}

This study revealed that the addition of vermicompost extended the thermophilic period at a higher temperature, accelerated the degradation of organic matters, and promoted the stability and fertilizer efficiency of composts. Besides, the potentially beneficial taxa genera Actinomadura and Chryseolinea were increased, while the pathogenic related Luteimonas and Stenotrophomonas were reduced. And activities of metabolic functional genes against on carbohydrate, amino acid and xenobiotics were enhanced during the thermophilic phase. Correlation analysis indicated that $\mathrm{NO}_{3}{ }^{-} \mathrm{-}$ and $\mathrm{Gl}$ were the strongest environmental factors for bacterial communities, and environmental information processing and metabolism were the primary metabolic pathways with vermicompost amendment. This work strengthens the understanding of functional genes of bacterial community in response to environmental factors influenced by additive vermicompost in swine manure composting.

\section{Declarations}

Ethics approval and consent to participate Not applicable.

Consent for publication Not applicable.

Availability of data and materials Not applicable. 
Competing interests The authors declare that they have no competing interests.

Authors' contributions Xiaoxia Hao distributed the questionnaires, collected the samples, analyzed the results, and wrote the manuscript; Xinyuan Ma determined the biochemical analyses; Lin Bai guided the study elaboration process and corrected the wording. All authors have read and approved the final manuscript.

\section{Acknowledgement}

This research was financially supported by the National Natural Science Foundation of China [31702156], and the Sichuan Swine Innovation Team Construction Project of National Modern Agricultural Industry Technology System of China [sccxtd-2021-08].

\section{References}

Adhikary S (2012) Vermicompost, the story of organic gold: A review. Agric. Sci., 3: 905-917. https://doi.org/10.4236/as.2012.37110.

Aira M, Domínguez J (2009) Microbial and nutrient stabilization of two animal manures after the transit through the gut of the earthworm Eisenia fetida (Savigny, 1826). J. Hazard. Mater. 161: 1234-1238. https://doi.org/10.1016/j.jhazmat.2008.04.073.

Anderson Craig R, Condron Leo M, Clough Tim J, Fiers M, Stewart A, Hill RA, Sherlock Robert R (2011) Biochar induced soil microbial community change: Implications for biogeochemical cycling of carbon, nitrogen and phosphorus. Pedobiologia, 54: 309 - 320. https://doi.org/10.1016/j.pedobi.2011.07.005.

Awasthi MK, Pandey AK, Khan J, Bundela PS, Wong JWC, Selvam A (2014) Evaluation of thermophilic fungal consortium for organic municipal solid waste composting. Bioresour. Technol. 168: 214-221. https://doi.org/10.1016/j.biortech.2014.01.048.

Bremner JM, Mulvaney CS (1982) Nitrogen total. In: Page AL, Miller RH, Keeney DR (Ed.), Methods of soil analysis. Am. Soc. Agronomy, Madison, Wilcosin, pp 575-624.

Chan MT, Selvam A, Wong JWC (2016) Reducing nitrogen loss and salinity of 'struvite" food waste composting by zeolite amendment. Bioresour. Technol. 200: 838-844.

https://doi.org/10.1016/j.biortech.2015.10.093.

Chen H, Zhang Y, Awasthi SK, Liu T, Zhang Z, Awasthi MK (2020) Effect of red kaolin on the diversity of functional genes based on Kyoto Encyclopedia of Genes and Genomes pathways during chicken manure composting. Bioresour. Technol. 311: 123584. https://doi.org/10.1016/j.biortech.2020.123584.

Chen Z, Wang Y, Wen Q (2018) Effects of chlortetracycline on the fate of multi-antibiotic resistance genes and the microbial community during swine manure composting. Environ. Pollut. 237: 977-987. https://doi.org/10.1016/j.envpol.2017.11.009. 
Das M, Uppal HS, Singh R, Beri S, Mohan KS, Gupta VC, Adholeya A (2011) Co-composting of physic nut (Jatropha curcas) deoiled cake with rice straw and different animal dung. Bioresour. Technol. 102: 65416546. https://doi.org/10.1016/j.biortech.2011.03.058.

Edwards CA, Burrows I (1988) The potential of earthworm composts as plant growth media. In: Edward, C.A. and E.F. Neuhauser (Ed.), Earthworms in waste and environment management. SPB Academic Press, The Hague, pp, 21-32.

Ermolaev E, Sundberg C, Pell M, Smårs S, Jönsson H (2019) Effects of moisture on emissions of methane, nitrous oxide and carbon dioxide from food and garden waste composting. J. Clean. Prod. https://doi.org/10.1016/j.jclepro.2019.118165.

Gajalakshmi S and Abbasi SA (2004) Earthworms and vermicomposting. Indian J. Biotechnol. 3: 486494.

Gu WJ, Zhang FB, Xu PZ, Tang SH, Xie KZ, Huang X, Huang QY (2011) Effects of sulphur and Thiobacillus thioparus on cow manure aerobic composting. Bioresour. Technol. 102: 6529-6535. https://doi.org/10.1016/j.biortech.2011.03.049.

Guo A, Gu J, Wang X, Zhang R, Yin Y, Sun W, Tuo X, Zhang L (2017) Effects of superabsorbent polymers on the abundances of antibiotic resistance genes, mobile genetic elements, and the bacterial community during swine manure composting. Bioresour. Technol. 244: 658-663.

https://doi.org/10.1016/j.biortech.2017.08.016.

Harshitha J, Krupanidhi S, Kumar S, Wong J (2016). Design and development of indoor device for recycling of domestic vegetable scrap. Environ. Technol. 37: 326-334.

https://doi.org/10.1080/09593330.2015.1069896.

Jurado M, Lopez MJ, Suarez-Estrella F, Vargas-Garcia MC, Lopez-Gonzalez JA, Moreno J (2014) Exploiting composting biodiversity: study of the persistent and biotechnologically relevant microorganisms from lignocellulose-based composting. Bioresour. Technol. 162: 283-293. https://doi.org/10.1016/j.biortech.2014.03.145.

Langille M, Zaneveld J, Caporaso JG, McDonald D, Knights D, Reyes J, Clemente J, Burkepile D, Vega Thurber R, Knight R, Beiko R, Huttenhower C (2013) Predictive functional profiling of microbial communities using 16S rRNA marker gene sequences. Nat. Biotechnol. 31: 814-821. https://doi.org/10.1038/nbt.2676.

Li R, Wang JJ, Zhang Z, Shen F, Zhang G, Qin R, Li X, Xiao R (2012) Nutrient transformations during composting of pig manure with bentonite. Bioresour. Technol. 121: 362-368. https://doi.org/10.1016/j.biortech.2012.06.065. 
Li Y, Wang X, Chen Q, Hou Y, Xia Q, Zhao P (2016) Metabolomics Analysis of the Larval Head of the Silkworm, Bombyx mori. Int. J. Mol. Sci. 17: 1460. https://doi.org/10.3390/ijms17091460.

Liu L, Wang S, Guo X, Zhao T, Zhang B (2018a) Succession and diversity of microorganisms and their association with physicochemical properties during green waste thermophilic composting. Waste Manage. 73: 101-112. https://doi.org/10.1016/j.wasman.2017.12.026.

Liu Y, Wang W, Xu J, Xue H, Stanford K, McAllister TA, Xu W (2018b) Evaluation of compost, vegetable and food waste as amendments to improve the composting of $\mathrm{NaOH} / \mathrm{NaClO}$ contaminated poultry manure. PLoS ONE, 13: e0205112. https://doi.org/10.1371/journal.pone.0205112.

Mao H, Lv Z, Sun H, Li R, Zhai B, Wang Z, Awasthi MK, Wang Q, Zhou L (2018) Improvement of biochar and bacterial powder addition on gaseous emission and bacterial community in pig manure compost. Bioresour. Technol. 258: 195-202. https://doi.org/10.1016/j.biortech.2018.02.082.

McKellar ME and Nelson EB (2003) Compost-Induced Suppression of Pythium Damping-Off Is Mediated by Fatty-Acid-Metabolizing Seed-Colonizing Microbial Communities. Appl. Environ. Microbiol. 69: 452460. https://doi.org/10.1128/AEM.69.1.452-460.2003.

Meng X, Liu B, Xi C, Luo X, Yuan X, Wang X, Zhu W, Wang H, Cui Z (2018) Effect of pig manure on the chemical composition and microbial diversity during co-composting with spent mushroom substrate and rice husks. Bioresour. Technol. 251: 22-30. https://doi.org/10.1016/j.biortech.2017.09.077.

Olli M (2018) The effect of vermicompost on the growth and quality of cress (lepidium sativum). J. Agr. Sci. 1: 25-28. https://doi.org/10.15159/jas.18.02.

Park S, Akira Y, Kogure K (2014) The Family Rhodothermaceae. In: Rosenberg E., DeLong E.F., Lory S., Stackebrandt E., Thompson F. (Ed.) The Prokaryotes. Springer, Berlin, Heidelberg, pp. 849-856. https://doi.org/10.1007/978-3-642-38954-2_141.

Pathma J, Sakthivel N (2012) Microbial diversity of vermicompost bacteria that exhibit useful agricultural traits and waste management potential. Springerplus. 1: 26. https://doi.org/10.1186/2193-1801-1-26.

Qian X, Shen G, Wang Z, Guo C, Liu Y, Lei Z, Zhang Z (2014) Co-composting of livestock manure with rice straw: Characterization and establishment of maturity evaluation system. Waste Manage. 34: 530-535. https://doi.org/10.1016/j.wasman.2013.10.007.

Ren G, Xu X, Qu J, Zhu L, Wang T (2016) Evaluation of microbial population dynamics in the cocomposting of cow manure and rice straw using high throughput sequencing analysis. World $\mathrm{J}$. Microbiol. Biotechnol. 32:101. https://doi.org/10.1007/s11274-016-2059-7.

Singh A, Singh GS (2017) Vermicomposting: A sustainable tool for environmental equilibria. Environ. Qual. Manage. 27: 23-40. https://doi.org/10.1002/tqem.21509. 
Soobhany N, Mohee R, Garg V.K (2017) Inactivation of bacterial pathogenic load in compost against vermicompost of organic solid waste aiming to achieve sanitation goals: a review. Waste Management, 64: 51-62. https://doi.org/10.1016/j.wasman.2017.03.003.

Teixeira LM, Merquior VLC (2014) The Family Moraxellaceae. In: Rosenberg E., DeLong E.F., Lory S., Stackebrandt E., Thompson F. (Ed.), The Prokaryotes. Springer, Berlin, Heidelberg, pp. 443-476. https://doi.org/10.1007/978-3-642-38922-1_245.

Yang L, Wang X, Cui S, Ren Y, Yu J, Chen N, Xiao Q, Guo L, Wang R (2019) Simultaneous removal of nitrogen and phosphorous by heterotrophic nitrification-aerobic denitrification of a metal resistant bacterium Pseudomonas putida strain NP5. Bioresour. Technol. 285: 121360. https://doi.org/10.1016/j.biortech.2019.121360.

Wang K, Mao H, Wang Z, Tian Y (2018) Succession of organics metabolic function of bacterial community in swine manure composting. J. Hazard. Mater. 360: 471-480.

https://doi.org/10.1016/j.jhazmat.2018.08.032.

Wang Q, Li R, Cai H, Awasthi MK, Zhang ZQ, Wang JJ, Ali A, Amanullah M (2016) Improving pig manure composting efficiency employing Ca-bentonite. Ecol. Eng. 87: 157-161.

https://doi.org/10.1016/j.ecoleng.2015.11.032.

Wang T, Cheng L, Zhang W, Xu X, Meng Q, Sun X, Liu H, Li H, Sun Y (2017) Anaerobic AmmoniumOxidizing Bacteria in Cow Manure Composting. Journal of microbiology and biotechnology, 27: 12881299. https://doi.org/10.4014/jmb.1702.02065.

Wei H, Wang L, Hassan M, Xie B (2018) Succession of the functional microbial communities and the metabolic functions in maize straw composting process. Bioresour. Technol. 256: 333-341. https://doi.org/10.1016/j.biortech.2018.02.050.

Xi B, He X, Dang Q, Yang T, Li M, Wang X, Li D, Tang J (2015) Effect of multi-stage inoculation on the bacterial and fungal community structure during organic municipal solid wastes composting. Bioresour. Technol. 196: 399-405. https://doi.org/10.1016/j.biortech.2015.07.069.

Zhang C, Gao Z, Shi W, Li L, Tian R, Huang J, Lin R, Wang B, Zhou B (2020) Material conversion, microbial community composition and metabolic functional succession during green soybean hull composting. Bioresour. Technol. 316: 123823. https://doi.org/10.1016/j.biortech.2020.123823.

Zhang J, Chen G, Sun H, Zhou S, Zou G (2016) Straw biochar hastens organic matter degradation and produces nutrient-rich compost. Bioresour. Technol. 200: 876-883.

https://doi.org/10.1016/j.biortech.2015.11.016.

Zhang L, Sun XY (2014) Changes in physical chemical and microbiological properties during the twostage co-composting of green waste with spent mushroom compost and biochar. Bioresour. Technol. 
171: 274-284. https://doi.org/10.1016/j.biortech.2014.08.079.

Zhang N, Chen H, Lyu Y, Wang Y (2019) Nitrogen removal by a metal-resistant bacterium, Pseudomonas putida ZN1, capable of heterotrophic nitrification-aerobic denitrification. Journal of Chemical Technology and Biotechnology, 94: 1165-1175. https://doi.org/10.1002/jctb.5863.

Zhou G, Xu X, Qiu X, Zhang J (2019) Biochar influences the succession of microbial communities and the metabolic functions during rice straw composting with pig manure. Bioresour. Technol. 272: 10-18. https://doi.org/10.1016/j.biortech.2018.09.135.

Zhu L, Zhao Y, Zhang W, Zhou H, Chen X, Li Y, Wei D, Wei Z (2019) Roles of bacterial community in the transformation of organic nitrogen toward enhanced bioavailability during composting with different wastes. Bioresour. Technol. 285: 121326. https://doi.org/10.1016/j.biortech.2019.121326.

\section{Figures}



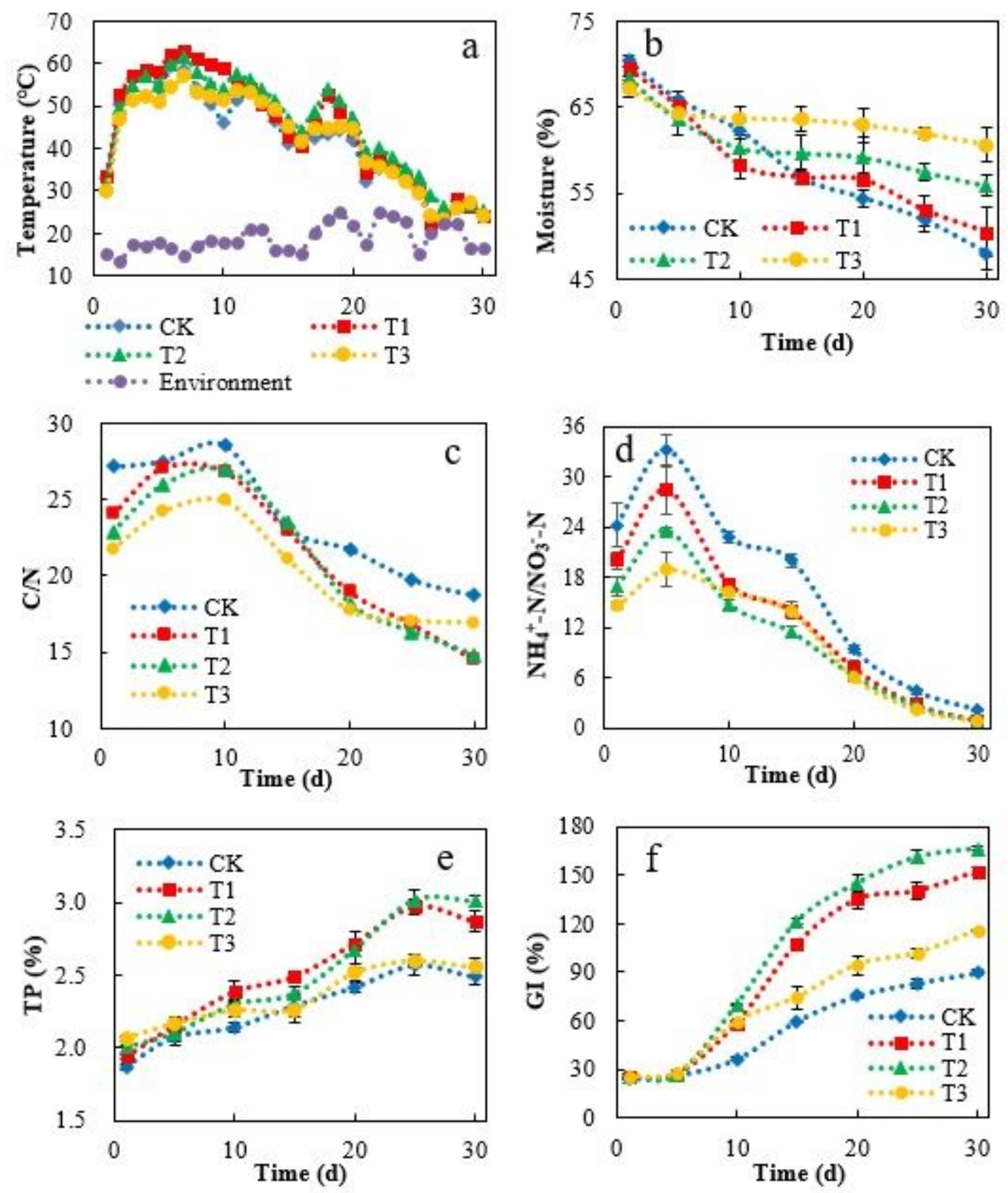

Figure 1

Variations of temperature, moisture, $\mathrm{C} / \mathrm{N}$ ratio, $\mathrm{NH} 4+-\mathrm{N} / \mathrm{NO}--\mathrm{N}$ ratio, $\mathrm{TP}$ and $\mathrm{Gl}$ in composting 

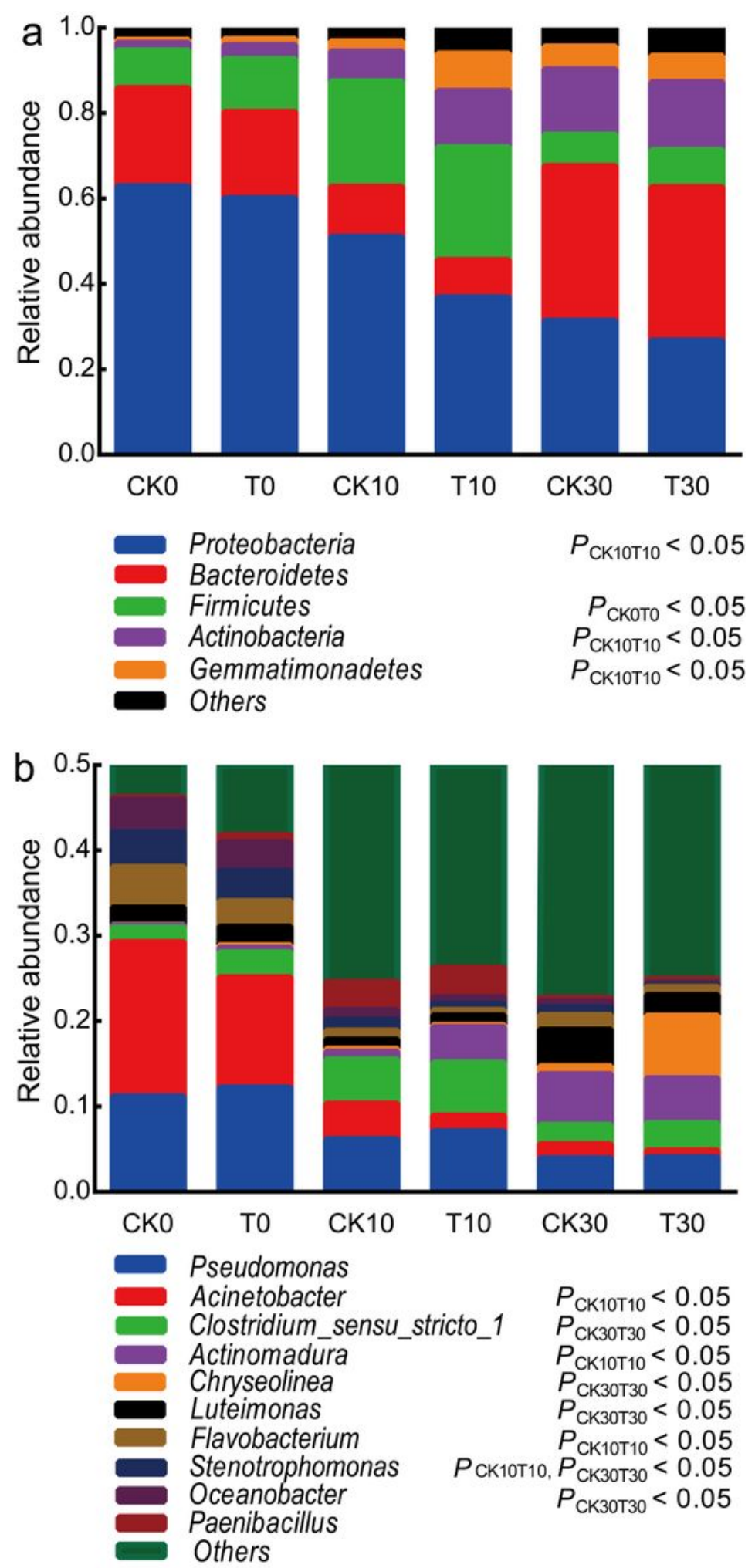

Figure 2

The bacterial community composition at phylum-level (a) and top 10 on genus level (b) in the compost at different treatments. $T$ : treatments $(T 1, T 2$ and $T 3) ; 0,10,30$ : sampling time points on day $0,10,30$. (Welch's t-test) 
a

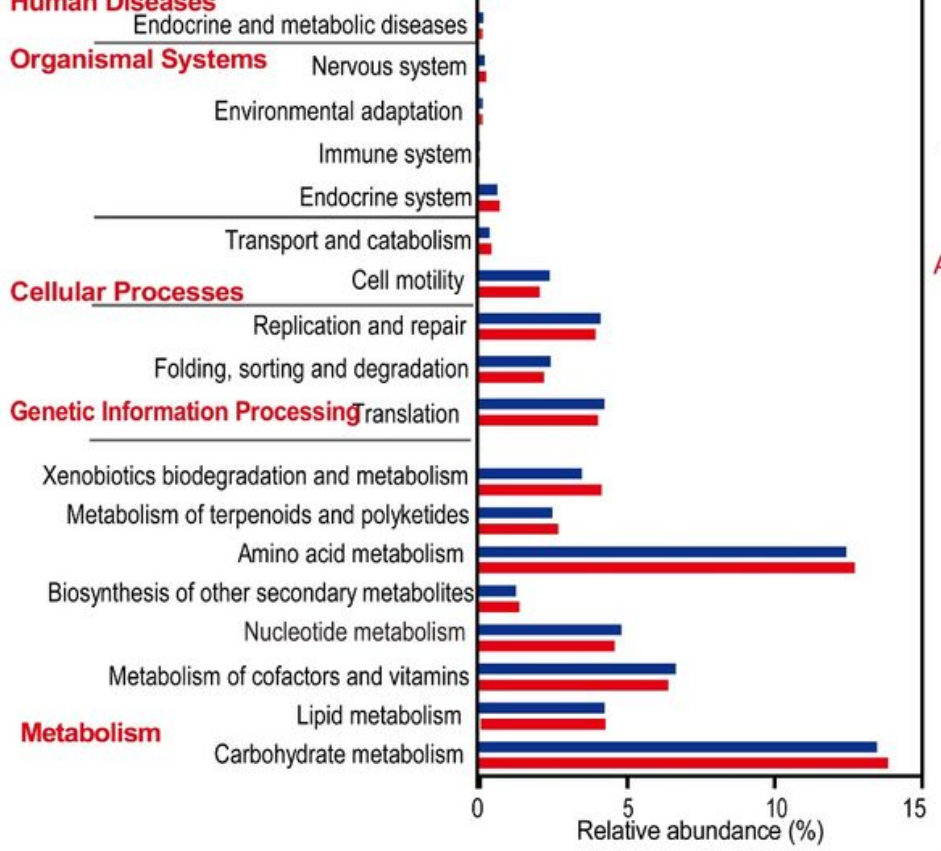

b

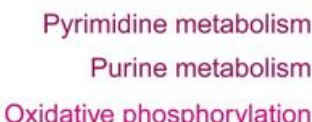

Carbon fixation pathways in prokaryotes

Glycine, serine and threonine metabolism Alanine, aspartate and glutamate metabolism Arginine and proline metabolism

Glyoxylate and dicarboxylate metabolism Amino sugar and nucleotide sugar metabolism

Butanoate metabolism

Pyruvate metabolism

Glycolysis / Gluconeogenesis 2-Oxocarboxylic acid metabolism

Fatty acid metabolism

Biosynthesis of amino acids

Carbon metabolism

Aminoacyl-tRNA biosynthesis

Ribosome

ABC transporters

Two-component system

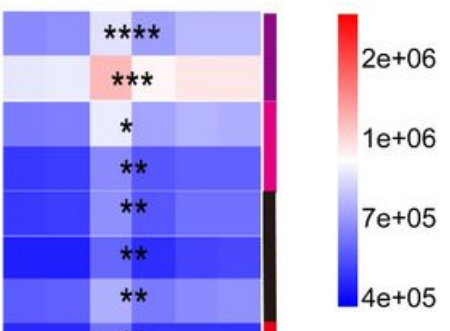

$$
\text { 옹 항옿곃융령 }
$$

M_NM

M_EM

M_AAM

M_CM

M_GOM

GIP_T

EIP_MT

EIP_ST

\section{Figure 3}

The top 20 significantly different biochemical metabolic pathways at the level 2 (a) and top 20 functional gene numbers at the level 3 (b). CK: control group; $T$ : treatments (T1, T2 and T3); 0, 10, 30: sampling time points on day $0,10,30$ 
a

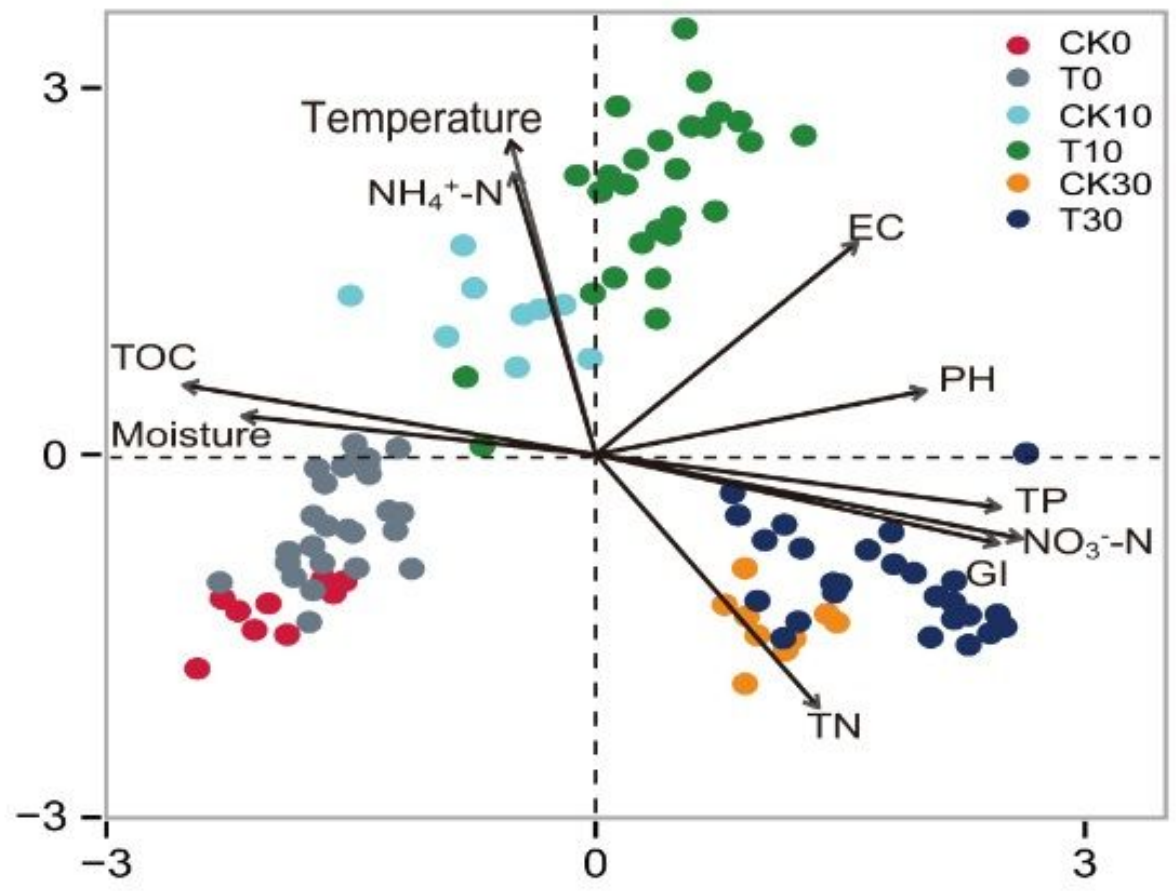

b

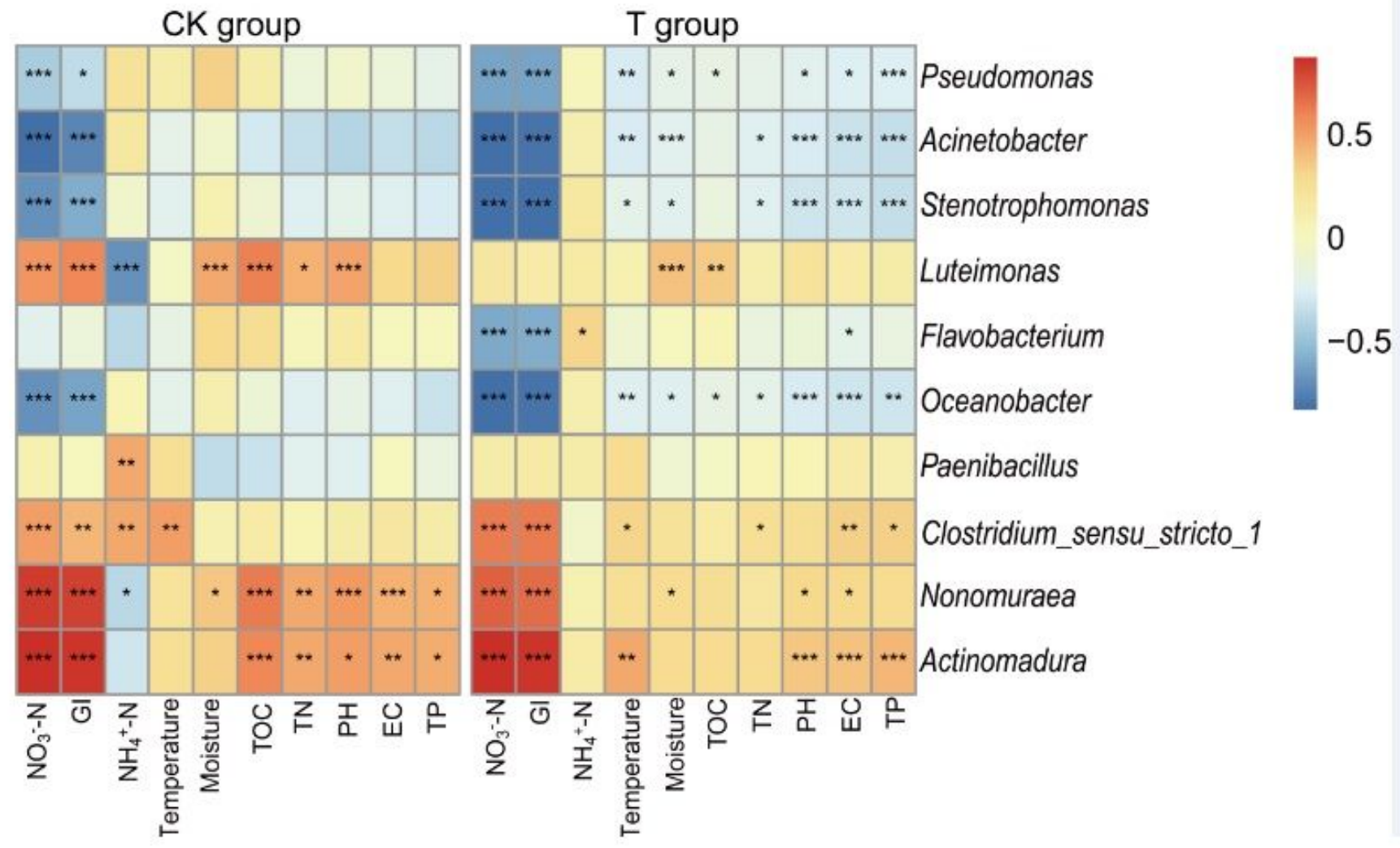

\section{Figure 4}

The correlation between bacterial taxonomic distribution at genus level and compost parameters. RDA on all samples and environmental factors (a); Heatmap of top 10 genera and environmental factors (b). CK: control group; $\mathrm{T}$ : treatments (T1, T2 and T3); $0,10,30$ : sampling time points on day $0,10,30$. ( $*$ : $\mathrm{P}<0.05$, $\star \star: P<0.01, \star \star \star: P<0.001)$ 


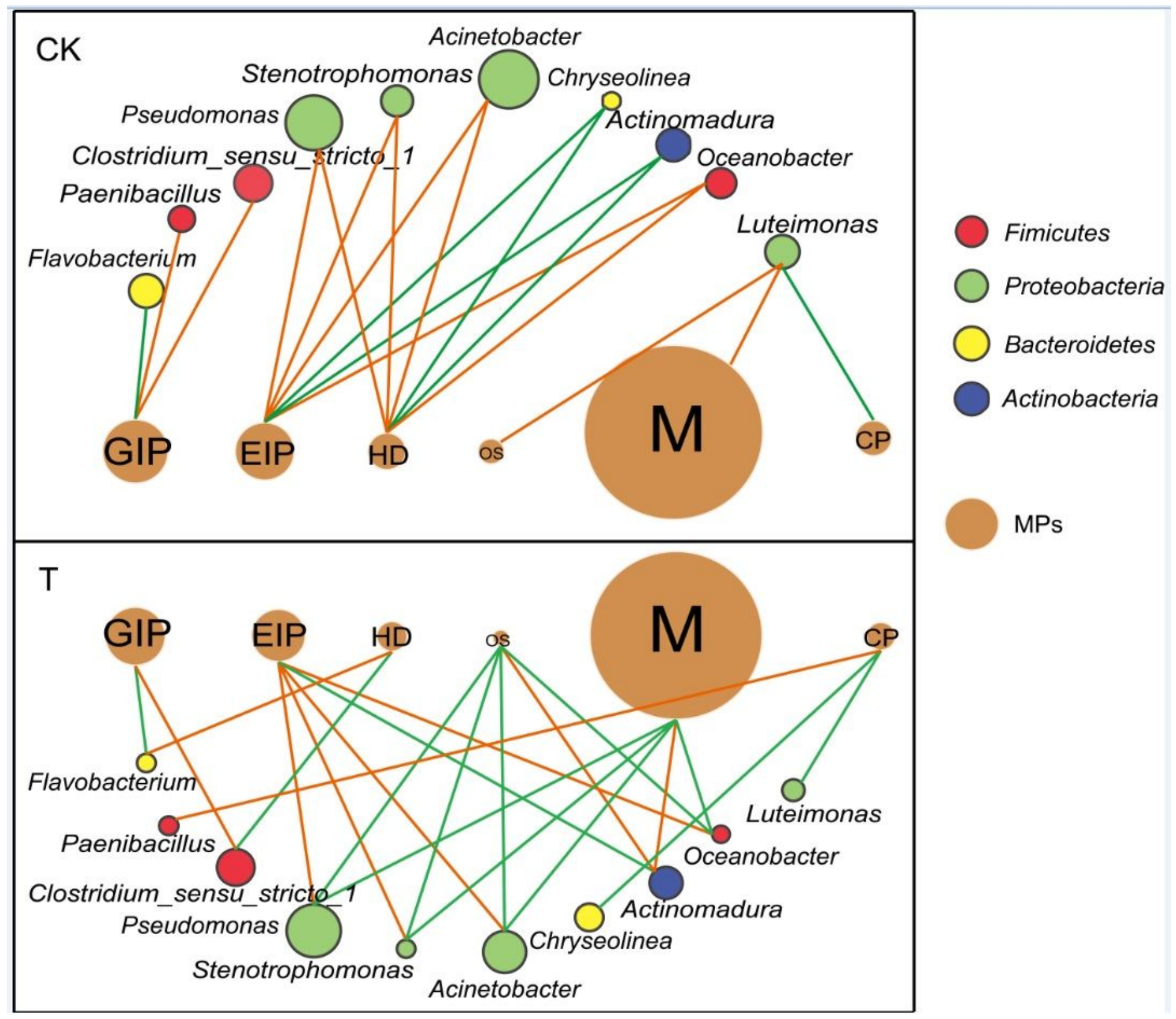

Figure 5

Network analysis of bacterial communities and their metabolic pathways in treatment and control groups. A connection represents a significant positive correlation $(p<0.05)$ according to Spearman's rank analysis $(r>0.6)$. The red and green lines represent positive and negative correlations, respectively. The node size represents the abundances of bacteria/microbial metabolism. MPs: metabolic pathways, M: metabolism, CP: Cellular processes, EIP: Environmental information processing, GIP: Genetic information processing, HD: Human diseases, OS: Organismal systems

\section{Supplementary Files}

This is a list of supplementary files associated with this preprint. Click to download. 
- SupplementaryMaterials.pdf

Page 22/22 